https://helda.helsinki.fi

\title{
Concomitant drugs with buprenorphine user deaths
}

\section{Mariottini, Claudia}

2021-01-01

Mariottini , C , Kriikku , P \& Ojanperä , I 2021 , ' Concomitant drugs with buprenorphine user deaths ' , Drug and Alcohol Dependence , vol. 218 , 108345 . https://doi.org/10.1016/j.drugalcdep.2020.108345

http://hdl.handle.net/10138/324966

https://doi.org/10.1016/j.drugalcdep.2020.108345

publishedVersion

Downloaded from Helda, University of Helsinki institutional repository.

This is an electronic reprint of the original article.

This reprint may differ from the original in pagination and typographic detail.

Please cite the original version. 


\title{
Concomitant drugs with buprenorphine user deaths
}

\author{
Claudia Mariottini $^{\mathrm{a}, \mathrm{b}}$, Pirkko Kriikku ${ }^{\mathrm{b}, \mathrm{a}}$, Ilkka Ojanperä ${ }^{\mathrm{a}, \mathrm{b}, *}$ \\ ${ }^{a}$ Department of Forensic Medicine, University of Helsinki, P.O. Box 40, 00014 Helsinki, Finland \\ ${ }^{\mathrm{b}}$ Forensic Toxicology Unit, Finnish Institute for Health and Welfare, P.O. Box 30, 00271 Helsinki, Finland
}

\section{A R T I C L E I N F O}

\section{Keywords:}

Buprenorphine-related death

Concomitant use

Benzodiazepines

Pregabalin

Alcohol

\begin{abstract}
A B S T R A C T
Background: Buprenorphine is abused in several countries notwithstanding its benefits as an analgesic and as an opioid agonist treatment medication. Benzodiazepines and alcohol have previously been associated with buprenorphine toxicity. This study elucidates the role of emerging concomitant drugs in different groups of buprenorphine user deaths.

Methods: All cases in the Finnish national post-mortem toxicology database from 2016-2019 in which buprenorphine or norbuprenorphine was a laboratory finding in any post-mortem specimen and age at death of 15-64 years were investigated for cause and manner of death, concurrent drug and alcohol findings, age, and gender. Results: There were 792 deaths with a buprenorphine finding, of which buprenorphine was implicated in poisoning without other opioids in 271 cases (34\%). In this group of buprenorphine poisoning deaths, concomitant benzodiazepines were found in $94 \%$ (clonazepam $53 \%$ ), illicit drugs in $63 \%$, gabapentinoids in 50 $\%$ (pregabalin $41 \%$ ), alcohol in $41 \%$, antidepressants in $32 \%$, and antipsychotics in $28 \%$ of cases; only three deaths showed no benzodiazepines, alcohol, or gabapentinoids. Polydrug use was common regardless of the cause of death. In the age group 15 to 24 years, concomitant use of benzodiazepines and illicit drugs, and buprenorphine poisoning were more prevalent than in the age group 25-64 years.

Conclusions: The unprecedentedly high concomitant use of benzodiazepines in buprenorphine user deaths obscures other possible pharmacological risk factors for buprenorphine poisoning that could be relevant for prevention. Higher mortality in the younger age group suggests particularly unsafe drug use patterns that should be addressed.
\end{abstract}

\section{Introduction}

Buprenorphine is a semi-synthetic opioid and is used to treat moderate-to-severe and usually chronic pain. It is a common medication for opioid use disorder patients in opioid agonist treatment (OAT), which aims to minimize the social and health harms related to opioid abuse.

Buprenorphine is a weak partial $\mu$-opioid receptor agonist and a weak $\kappa$-opioid receptor antagonist. The drug has a higher affinity, but lower intrinsic activity compared to full $\mu$-opioid agonists, such as methadone. Buprenorphine preferentially binds to the opioid receptor and displaces lower affinity opioids without activating the receptor to a similar extent. Respiratory depression is a serious adverse effect of opioids that can lead to coma and death. Due to the properties described above, buprenorphine exhibits clinically slow onset of action and ceiling respiratory effects, supporting its safety profile compared to other opioids. Buprenorphine dissociates from opioid receptors very slowly, resulting in a long duration of action (Jasinski et al., 1978; Walsh et al., 1995; Yassen et al., 2007; Davis et al., 2018).

OAT is mostly performed with buprenorphine or methadone and the treatment is associated with lower rates of overdose death and all-cause mortality (Clausen et al., 2009; Degenhardt et al., 2011; White et al., 2015). Marteau et al. investigated the relative safety of buprenorphine and methadone for OAT and observed that buprenorphine is six times safer than methadone with regard to overdose risk among the general population (Marteau et al., 2015). In 2015, $63 \%$ of Finnish OAT patients received buprenorphine and $37 \%$ received methadone (EMCDDA, 2019a). Despite the benefits of buprenorphine OAT, the drug is associated with abuse and diversion. Substantial buprenorphine abuse has been reported in several countries, including Australia, Finland, France, Sweden, and USA (Yokell et al., 2011; Li et al., 2016). In Finland, reports of high-dose buprenorphine abuse date back to the late 1990s and coincide with the initiation of OAT.

Several studies have addressed the significant role of buprenorphine

\footnotetext{
* Corresponding author at: Department of Forensic Medicine, University of Helsinki, P.O. Box 40, 00014 Helsinki, Finland.

E-mail address: ilkka.ojanpera@helsinki.fi (I. Ojanperä).
} 
in the Finnish drug scene (Uosukainen et al., 2013a, b; Uosukainen et al., 2014; Launonen et al., 2016; Kauhanen and Tiihonen, 2017). Finland has an opioid abuse profile different from the neighboring Nordic countries, with a very limited supply of heroin and less methadone abuse. Buprenorphine accounts for about one third of the total drug poisoning mortality (5.84 per 100,000 for inhabitants aged 15-64 in 2017) (Simonsen et al., 2020). Uosukainen et al. studied clients seeking treatment for buprenorphine abuse and found that daily buprenorphine abuse, intravenous administration, and concurrent substance use were common (Uosukainen et al., 2013a).

A large proportion of opioid-dependent people in Finland started their opioid use with buprenorphine purchased directly from the street trade. Buprenorphine addiction is a particularly Finnish problem, as more than $80 \%$ of high-risk opioid users have used buprenorphine as their main drug (Kauhanen and Tiihonen, 2017). The abused buprenorphine is predominantly diverted pharmaceutical grade mono-buprenorphine tablets smuggled into the country from abroad, especially from France (Finnish Customs, 2018).

OAT based on buprenorphine is often implemented using a sublingual combination product containing buprenorphine and naloxone. The opioid antagonist naloxone in the coformulation should prevent parenteral use of the product but allow sublingual dosing. Naloxone acts as a full antagonist for opioid receptors, thus reducing the likelihood of parenteral use, including intravenous and nasal administration (Orman and Keating, 2009). With the exception of pregnant women treated with mono-buprenorphine, buprenorphine/naloxone has been the sole buprenorphine product for treating OAT patients in Finland since 2007 until 2018, after which a prolonged-release subcutaneous buprenorphine injection treatment has been initiated for a growing proportion of patients. Buprenorphine/naloxone also has intravenous abuse potential, although the potential is lower than with buprenorphine alone (Comer et al., 2002; Alho et al., 2007); the combination product is equally liable to cause fatal poisonings (Häkkinen et al., 2013; Kriikku et al., 2018).

Differences in blood concentrations of buprenorphine or its metabolite norbuprenorphine between buprenorphine-induced deaths and cases with other causes of death are not clinically relevant (Häkkinen et al., 2012; Seldén et al., 2012), suggesting that explanatory factors other than plain buprenorphine overdose exist. Following early observations on the involvement of concomitant drugs (Tracqui et al., 1998), there is increasing evidence that buprenorphine-related fatalities are associated with the use of central nervous system depressants, such as alcohol and benzodiazepines, which potentiate respiratory depression (Mégarbane et al., 2006; Ferrant et al., 2011; Jones et al., 2012; Häkkinen et al., 2012; Seldén et al., 2012). Despite the widely recognized problem of concurrent use of sedative/hypnotic drugs among people who use drugs, our understanding of the factors incidental to fatal buprenorphine-related deaths is still limited (Wightman et al., 2020).

Although the rates of fatal and non-fatal opioid overdose have been extensively studied among patients receiving OAT (Gibson and Degenhardt, 2007; Wikner et al., 2014; Kelty and Hulse, 2017; Abrahamsson et al., 2017; Sordo et al., 2017), less information is available from the perspective of cause-of-death determination of people who use drugs. In the present study, we assess recent trends in buprenorphine-related deaths in Finland by focusing on the deceased buprenorphine users' age distribution and polydrug use during the 4-year period of 2016-2019, with a special emphasis on the young age group 15-24 years. In addition to concomitant benzodiazepines and alcohol, the prevalence of emerging psychoactive drugs, such as the gabapentinoids pregabalin and gabapentin, is elucidated in detail, taking advantage of the comprehensive post-mortem toxicology investigation and the extensive national cause-of-death register available.

\section{Materials and methods}

\subsection{Data collection}

All sudden and unexpected deaths in Finland are investigated with a medico-legal autopsy initiated by the police and performed by a forensic pathologist. These include fatalities unexplained by disease or related to accidents, crime, suicide, poisoning, occupational disease, medical procedure, or war. Approximately $16 \%$ of all deaths undergo a medicolegal investigation. In approximately $75 \%$ of autopsy cases, a comprehensive post-mortem toxicology investigation is conducted by request of the forensic pathologist (12\% of all deaths). The research material included the forensic pathologist's referral, a brief description of the circumstances of death, the main autopsy findings, comprehensive laboratory analysis results, and information extracted from the death certificate (time of death, age, gender, cause of death, manner of death).

This was a retrospective study that consisted of all medico-legal autopsy cases of deceased persons aged 15-64 years in Finland from 2016-2019 with a buprenorphine or norbuprenorphine finding in any analyzed autopsy specimen (blood, urine, vitreous humor, liver, muscle). Two unidentified subjects were excluded.

In total, the study included 792 subjects who were divided into the following four groups by the authors:

Group A: Buprenorphine implicated in poisoning (i.e. the forensic pathologist had recorded buprenorphine in the death certificate as either the main cause or a secondary cause of fatal poisoning) without other opioids

Group B: Buprenorphine implicated in poisoning with other opioids;

Group C: Other poisoning, in which buprenorphine was a laboratory finding, but not implicated in the causes of death; and

Group D: Controls, in which buprenorphine was a laboratory finding but poisoning was not the cause of death.

\subsection{Statistical analysis}

All statistical analyses were performed using the Statistical Package for Social Sciences (SPSS version 26.0, IBM Inc., USA).

Medians were used to characterize the data since the values within a group were not normally distributed. The analysis of categorical variables (such as age, gender, and number of other drugs used) was performed using the nonparametric Kruskall-Wallis test followed by the multiple comparison test (Dunn's test). A p-value of $<0.05$ was considered statistically significant for all analyses.

\subsection{Ethical issues}

The study was carried out on the basis of the research permit THL/ 1922/6.02.00/2017, issued by the Finnish Institute for Health and Welfare, Finland. According to the Finnish legislation, no separate ethical approval is needed for studies that utilize de-identified registerbased data (Personal Data Act 523/1999).

\section{Results}

Buprenorphine or norbuprenorphine was detected in 792 postmortem investigations involving deceased persons aged 15-64 years in Finland during the 4-year study period of 2016-2019 (hereafter referred to as buprenorphine user deaths). Table 1 shows the number of cases, median age, manner of death, and the proportion of individuals aged 15-24 years in each of the four groups (A-D) and in the entire study population. Group $\mathrm{C}$ consisted of poisoning cases as follows: drugs other than buprenorphine $(\mathrm{N}=73,85 \%)$, ethanol $(\mathrm{N}=8,9 \%)$, carbon monoxide $(\mathrm{N}=4,5 \%)$, and methanol $(\mathrm{N}=1,1 \%)$.

Fig. 1 shows the annual numbers of all buprenorphine user deaths and separately the numbers for individuals aged 15-25 years. Of all deceased persons in the study, $84 \%$ were male. The proportion of 
Table 1

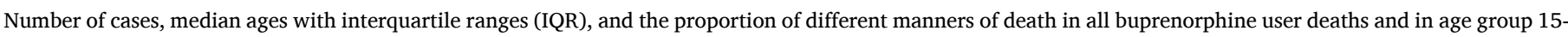
24 years for each user group A-D in Finland in 2016-2019.

\begin{tabular}{|c|c|c|c|c|c|c|c|c|c|c|c|c|c|c|c|}
\hline \multicolumn{2}{|c|}{ Group } & \multicolumn{2}{|c|}{ N (\%) } & \multirow{2}{*}{\multicolumn{2}{|c|}{$\frac{\text { Median age }}{\text { IQR), years }}$}} & \multicolumn{8}{|c|}{ Manner of death } & \multirow{2}{*}{\multicolumn{2}{|c|}{$\frac{\mathrm{N}(\%) \text {, age group }}{15-24 \text { years }}$}} \\
\hline & & & & & & $\mathrm{N}(\%$ & cident & $\mathrm{N}(\%$ & icide & $\mathrm{N}(\%$ & indetermined & $\mathrm{N}(\%$ & her* & & \\
\hline \multirow[t]{3}{*}{ A } & All & 271 & & 31 & $(23-39)$ & 245 & (90) & 13 & (5) & 13 & (5) & - & - & 79 & (29) \\
\hline & Males & 218 & $(80)$ & 32 & $(25-39)$ & 202 & (93) & 8 & (4) & 8 & (4) & - & - & 53 & (24) \\
\hline & Females & 53 & (20) & 26 & $(19-37)$ & 43 & (81) & 5 & (9) & 5 & (9) & - & - & 26 & (49) \\
\hline \multirow[t]{3}{*}{ B } & All & 99 & & 36 & $(26-42)$ & 88 & (89) & 3 & (3) & 8 & (8) & - & - & 20 & (20) \\
\hline & Males & 90 & (91) & 36 & $(26-42)$ & 79 & $(88)$ & 3 & (3) & 8 & (9) & - & - & 18 & (20) \\
\hline & Females & 9 & (9) & 39 & $(25-43)$ & 9 & (100) & - & - & - & - & - & - & 2 & (22) \\
\hline \multirow[t]{3}{*}{ C } & All & 86 & & 34 & $(27-43)$ & 61 & (71) & 14 & (16) & 11 & (13) & - & - & 12 & (14) \\
\hline & Males & 70 & (81) & 37 & $(27-44)$ & 52 & (74) & 9 & (13) & 9 & (13) & - & - & 7 & (10) \\
\hline & Females & 16 & (19) & 30 & $(24-34)$ & 9 & (56) & 5 & (31) & 2 & (13) & - & - & 5 & (31) \\
\hline \multirow[t]{3}{*}{ D } & All & 336 & & 36 & $(28-47)$ & 46 & (14) & 71 & (21) & 13 & (4) & 206 & (61) & 41 & (12) \\
\hline & Males & 284 & (85) & 36 & $(29-46)$ & 42 & (15) & 62 & (22) & 11 & (4) & 169 & (60) & 31 & (11) \\
\hline & Females & 52 & (15) & 34 & $(27-50)$ & 4 & (8) & 9 & (17) & 2 & (4) & 37 & (71) & 10 & (19) \\
\hline \multirow[t]{3}{*}{ All } & All & 792 & & 34 & $(26-43)$ & 440 & (56) & 101 & (13) & 45 & (6) & 206 & (26) & 152 & (19) \\
\hline & Males & 662 & (84) & 35 & $(27-43)$ & 375 & (57) & 82 & (12) & 36 & (5) & 169 & (26) & 109 & (16) \\
\hline & Females & 130 & (16) & 30 & $(23-43)$ & 65 & (50) & 19 & (15) & 9 & (7) & 37 & (28) & 43 & (33) \\
\hline
\end{tabular}

Group A: Buprenorphine implicated in poisoning without other opioids.

Group B: Buprenorphine implicated in poisoning with other opioids.

Group C: Other poisoning, in which buprenorphine was a laboratory finding, but not implicated in the causes of death.

Group D: Controls, in which buprenorphine was a laboratory finding but poisoning was not the cause of death.

" Other manners of death included the following (N): disease (174), homicide (29), war (1), medical treatment (1), and occupational disease (1).
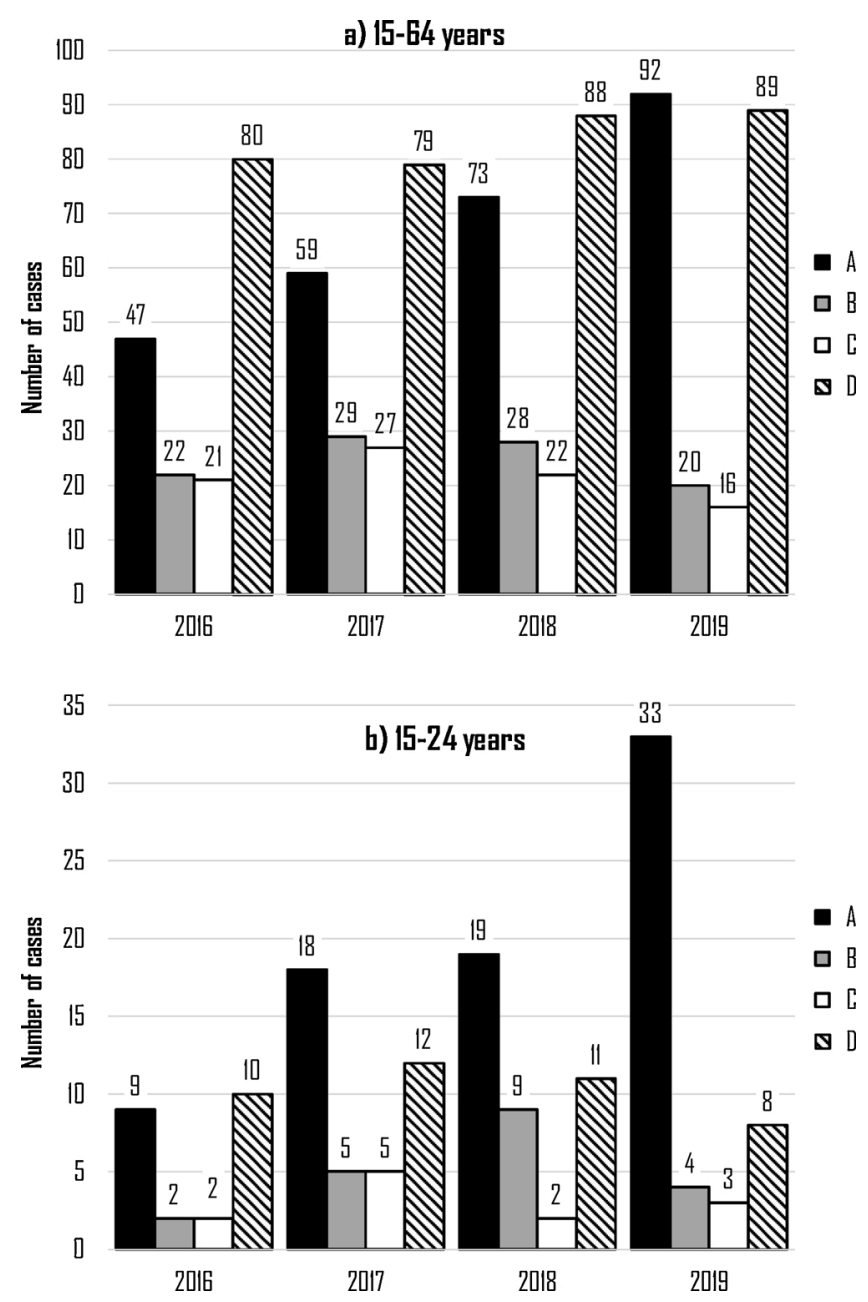

Fig. 1. Annual number of buprenorphine user deaths for each user group A-D in (a) all age groups and (b) in age group 15-24 years in Finland in 2016-2019. females was $20 \%, 9 \%, 19 \%$, and $15 \%$ in groups A to D, respectively. There were no significant differences in the proportion of females in the groups ( $\mathrm{p}=0.097)$.

The overall number of buprenorphine user deaths increased over the study period from 170 cases in 2016 to 217 cases in 2019 . The increase was mainly due to group A, as the proportion of group A deaths increased from $27.6 \%$ in 2016 to $42.4 \%$ in 2019. In the age group 15-24 years, the proportion of group A deaths increased from $39.1 \%$ in 2016 to $68.8 \%$ in 2019 . There were significantly more individuals aged $15-24$ years in group A than in any of the other groups $(\mathrm{p}<0.05)$. Of all deceased individuals aged 15-24 years, $52 \%$ were in group A, $13 \%$ in group B, $7.9 \%$ in group C, and $27 \%$ in group D.

Fig. 2 illustrates the number of buprenorphine user deaths divided into 5-year age groups. The median ages in each group are shown in Table 1 . The median age was significantly lower in group A when compared to the other groups ( $\mathrm{p}<0.001$ ).

Concomitant alcohol and drug findings in all buprenorphine user deaths are shown in Fig. 3 and in detail in Table 2. The average number of concomitant drugs per death case was $4.7,6.4,5.2$, and 4.2 in groups A to $\mathrm{D}$, respectively. All drugs included in the database search are shown in supplementary Table $1 \mathrm{~S}$.

Blood alcohol concentration was significantly more often above the laboratory cut-off $(0.2 \mathrm{~g} / \mathrm{kg})$ in groups $\mathrm{A}(\mathrm{p}<0.001)$ and $\mathrm{C}(\mathrm{p}<0.05)$ than in group D. Groups A and B had significantly more deaths with a concomitant benzodiazepine finding than group $\mathrm{D}(\mathrm{p}=0.001$ and $\mathrm{p}<$ 0.001 , respectively). Other opioids were significantly more often found in group B than in groups C and D $(p<0.001)$. Gabapentinoids were significantly more often found in groups $\mathrm{B}$ and A than in group $\mathrm{D}(\mathrm{p}<$ 0.05 and $p<0.001$, respectively). Pregabalin was significantly more often found in group B than in any other group $(\mathrm{p}<0.05)$. Pregabalin was more prevalent in group A than in group D $(p<0.001)$. There were no significant differences in the prevalence of antidepressants, antipsychotics, illicit drugs and new psychoactive substances, or other medicinal drugs between groups A to D ( $p>0.05)$.

Buprenorphine and alcohol without other drugs were found in six cases $(0.8 \%)$; three cases $(1 \%)$ were in group $\mathrm{A}$, one case $(1 \%)$ in group $\mathrm{C}$, and two cases $(0.6 \%)$ in group $\mathrm{D}$.

In group $\mathrm{A}$, among the 255 benzodiazepine positive cases, one (41 $\%)$, two (39\%), or three (13\%) different benzodiazepines were found. Respectively, in group B, among 93 cases, two (47\%), three (23\%), or one (17 \%) benzodiazepines were found; in group C, among 75 cases, 


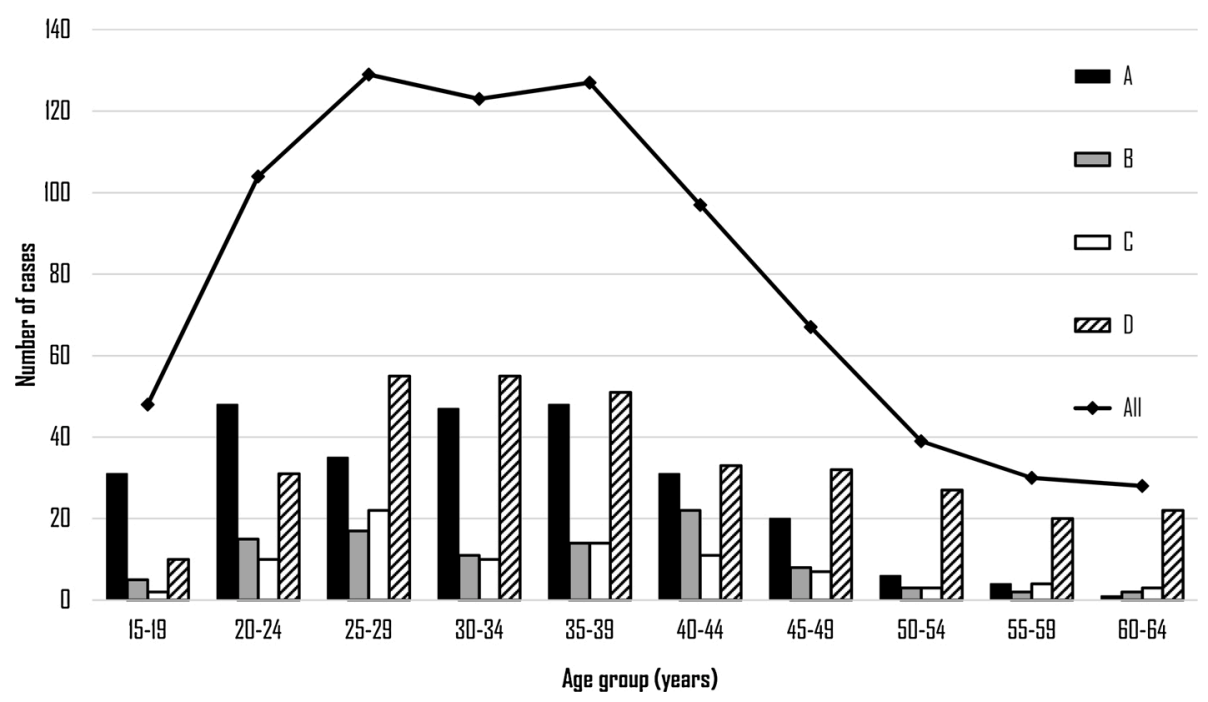

Fig. 2. Age distribution of buprenorphine user deaths.

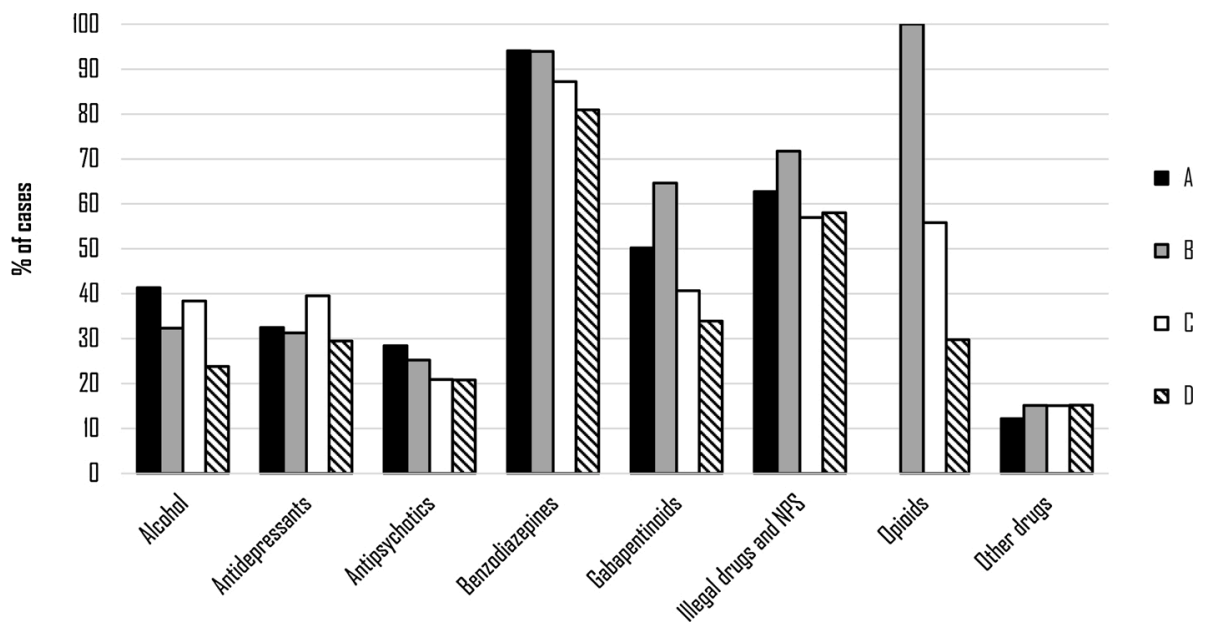

Fig. 3. Concomitant findings of alcohol and classes of drug in buprenorphine user deaths.

one (41\%) or two (37\%) benzodiazepines were found; in group D, among 272 cases, one (37\%), two (29\%) or three (11\%) benzodiazepines were found. Buprenorphine and a benzodiazepine without other drugs or alcohol were found in 24 cases (3\%); 11 cases (4\%) were in group A and 13 cases (4\%) in group D.

Both pregabalin and gabapentin were present in 45 cases (6\%); 14 cases (5\%) were in group A, $12(12 \%)$ in group B, $5(6 \%)$ in group C, and $14(4 \%)$ in group D. Buprenorphine and a gabapentinoid without other drugs or alcohol were found in one case (0.1\%; pregabalin in group D).

Table 3 compares the concomitant use of alcohol, benzodiazepines, gabapentinoids, and illicit and new psychoactive substances between the age groups 15-24 and 25-64 years. Concomitant use of benzodiazepines and illicit and new psychoactive substances was significantly more common in the age group 15-24 years than in 25-64 years $(\mathrm{p}=$ 0.001). Alcohol was more often used in the age group 25-64 years but the difference was not significant $(\mathrm{p}=0.109)$. In the age group 15-24 years, there were no significant differences in the concomitant use of alcohol, benzodiazepines, gabapentinoids, or illicit and new psychoactive substances between the buprenorphine user groups A to D (p >
0.05).

In the age group 25-64 years, concomitant use of benzodiazepines was significantly more common in groups A and B than in group D ( $\mathrm{p}<$ 0.001 and $\mathrm{p}=0.003$, respectively). Gabapentinoids were most commonly detected in group B; the difference was significant with all other user groups $(\mathrm{p}<0.05)$. Alcohol was most commonly detected in group A; the difference was significant when compared to groups B and $\mathrm{D}(\mathrm{p}<0.05$ and $\mathrm{p}<0.001$, respectively).

Of all 792 buprenorphine user deaths, buprenorphine alone was considered the main cause of fatal poisoning in 28 cases (4\%). However, there were no cases with buprenorphine as the only toxicological finding. In group A, there were three $(1 \%)$ cases in which benzodiazepines, alcohol, pregabalin, or gabapentin were not present. These cases are described in more detail below.

- Case 1. A 23-year-old female suffering from unstable personality disorder and psychotic symptoms had used alcohol, buprenorphine, cannabis, and ecstasy with her friends in the evening. In the morning, she was found dead in her bed. She had a history of using various 
Table 2

Concomitant findings of alcohol and different drugs in buprenorphine user deaths.

\begin{tabular}{|c|c|c|c|c|c|c|c|c|}
\hline \multirow[t]{2}{*}{ Substance } & \multicolumn{2}{|c|}{ Group A $(\mathrm{N}=271)$} & \multicolumn{2}{|c|}{ Group B $(N=99)$} & \multicolumn{2}{|c|}{ Group C $(\mathrm{N}=86)$} & \multicolumn{2}{|c|}{ Group D $(\mathrm{N}=336)$} \\
\hline & $\mathrm{N}$ & $(\%)$ & $\mathrm{N}$ & $(\%)$ & $\mathrm{N}$ & $(\%)$ & $\mathrm{N}$ & $(\%)$ \\
\hline Alcohol & 112 & (41) & 32 & (32) & 33 & (38) & 80 & (24) \\
\hline Antidepressants & 88 & (32) & 31 & (31) & 34 & (40) & 99 & (29) \\
\hline Amitriptyline/nortriptyline & 8 & (3) & 9 & (9) & 11 & (13) & 16 & (5) \\
\hline Bupropion & 7 & (3) & 2 & (2) & 9 & (10) & 9 & (3) \\
\hline Citalopram & 28 & (10) & 7 & (7) & 6 & (7) & 17 & (5) \\
\hline Mirtazapine & 28 & (10) & 16 & (16) & 6 & (7) & 37 & (11) \\
\hline Venlafaxine & 16 & (6) & 3 & (3) & 4 & (5) & 17 & (5) \\
\hline Antipsychotics & 77 & (28) & 25 & (25) & 18 & (21) & 70 & (21) \\
\hline Levomepromazine & 17 & (6) & 8 & (8) & 4 & (5) & 6 & (2) \\
\hline Olanzapine & 19 & (7) & 5 & (5) & 6 & (7) & 21 & (6) \\
\hline Quetiapine & 47 & (17) & 13 & (13) & 7 & (8) & 40 & (12) \\
\hline Benzodiazepines & 255 & (94) & 93 & (94) & 75 & (87) & 272 & (81) \\
\hline Alprazolam & 100 & (37) & 42 & (42) & 25 & (29) & 86 & (26) \\
\hline Chlordiazepoxide & 8 & (3) & 6 & (6) & 4 & (5) & 6 & (2) \\
\hline Clonazepam & 144 & (53) & 62 & (63) & 32 & (37) & 149 & (44) \\
\hline Diazepam & 93 & (34) & 56 & (57) & 33 & (38) & 123 & (37) \\
\hline Midazolam & 13 & (5) & 8 & (8) & 4 & (5) & 18 & (5) \\
\hline Oxazepam & 22 & (8) & 8 & (8) & 9 & (10) & 28 & (8) \\
\hline Temazepam & 19 & (7) & 7 & (7) & 5 & (6) & 34 & (10) \\
\hline Zopiclone & 8 & (3) & 4 & (4) & 4 & (5) & 8 & (2) \\
\hline Gabapentinoids & 136 & (50) & 64 & (65) & 35 & (41) & 114 & (34) \\
\hline Gabapentin & 39 & (14) & 22 & (22) & 13 & (15) & 38 & (11) \\
\hline Pregabalin & 111 & (41) & 54 & (55) & 27 & (31) & 90 & (27) \\
\hline Illicit drugs and NPS & 170 & (63) & 71 & (72) & 49 & (57) & 195 & (58) \\
\hline alpha-PVP & 6 & (2) & 3 & (3) & 4 & (5) & 3 & (1) \\
\hline Amphetamine/methamphetamine & 125 & (46) & 51 & (52) & 38 & (44) & 145 & (43) \\
\hline Cocaine & 7 & (3) & 6 & (6) & 6 & (7) & 11 & (3) \\
\hline GHB & 3 & (1) & 3 & (3) & 4 & (5) & 6 & (2) \\
\hline MDMA & 58 & (21) & 10 & (10) & 15 & (17) & 30 & (9) \\
\hline THC-COOH & 118 & (44) & 44 & (44) & 26 & (30) & 126 & (38) \\
\hline Opioids & - & & 99 & (100) & 48 & (56) & 100 & (30) \\
\hline Codeine & - & & 26 & (26) & 14 & (16) & 28 & (8) \\
\hline Fentanyl & - & & 7 & (7) & 9 & (10) & 7 & (2) \\
\hline Methadone & - & & 17 & (17) & 7 & (8) & 17 & (5) \\
\hline Morphine & - & & 7 & (7) & 1 & (1) & 5 & (1) \\
\hline Oxycodone & - & & 22 & (22) & 9 & (10) & 24 & (7) \\
\hline Tramadol & - & & 32 & (32) & 18 & (21) & 44 & (13) \\
\hline $\mathrm{U}-47,700$ & - & & 2 & (2) & 4 & (5) & 0 & $(0)$ \\
\hline Other drugs & 33 & (12) & 15 & (15) & 13 & (15) & 51 & (15) \\
\hline Hydroxyzine & 9 & (3) & 7 & (7) & 6 & (7) & 22 & (7) \\
\hline Methylphenidate & 11 & (4) & 5 & (5) & 3 & (3) & 12 & (4) \\
\hline
\end{tabular}

Footnote. NPS = new psychoactive substances.

Table 3

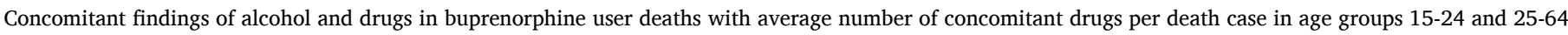
years.

\begin{tabular}{|c|c|c|c|c|c|c|c|c|c|c|c|}
\hline & \multicolumn{2}{|c|}{ Alcohol } & \multicolumn{3}{|c|}{ Benzodiazepines } & \multicolumn{3}{|c|}{ Gabapentinoids } & \multicolumn{3}{|c|}{ Illicit drugs and NPS } \\
\hline & $\mathrm{N}$ & $(\%)$ & $\mathrm{N}$ & $(\%)$ & Average findings/case & $\mathrm{N}$ & $(\%)$ & Average findings/case & $\mathrm{N}$ & $(\%)$ & Average findings/case \\
\hline \multicolumn{12}{|c|}{ Group A $(N=271)$} \\
\hline $15-24$ years & 22 & $(28)$ & 77 & (97) & 1.8 & 38 & (48) & 0.5 & 61 & (77) & 1.7 \\
\hline $25-64$ years & 90 & $(47)$ & 178 & (93) & 1.6 & 98 & (51) & 0.6 & 109 & (57) & 1.0 \\
\hline \multicolumn{12}{|c|}{ Group B $(N=99)$} \\
\hline $15-24$ years & 5 & (25) & 20 & $(100)$ & 2.1 & 11 & (55) & 0.7 & 18 & (90) & 1.4 \\
\hline $25-64$ years & 27 & (34) & 73 & $(92)$ & 5.1 & 53 & (67) & 0.8 & 53 & $(67)$ & 1.2 \\
\hline \multicolumn{12}{|c|}{ Group $C(N=86)$} \\
\hline $15-24$ years & 6 & $(50)$ & 11 & (92) & 1.8 & 6 & (50) & 0.5 & 9 & (75) & 1.2 \\
\hline $25-64$ years & 27 & (36) & 64 & (86) & 1.4 & 29 & (39) & 0.5 & 40 & (54) & 1.1 \\
\hline \multicolumn{12}{|c|}{ Group $D(N=336)$} \\
\hline $15-24$ years & 8 & (20) & 38 & (93) & 1.8 & 15 & (37) & 0.5 & 28 & (68) & 1.2 \\
\hline $25-64$ years & 72 & (24) & 234 & (79) & 1.4 & 99 & (34) & 0.1 & 167 & (57) & 0.9 \\
\hline
\end{tabular}

Footnote. NPS $=$ new psychoactive substances.

intoxicants and had had previous emergency department visits due to poisoning symptoms. Toxicology findings in blood were buprenorphine $(1.2 \mu \mathrm{g} / \mathrm{L})$, MDMA $(0.88 \mathrm{mg} / \mathrm{L})$, MDA $(0.09 \mathrm{mg} / \mathrm{L})$, THC $(1.6 \mu \mathrm{g} / \mathrm{L})$, THC-COOH $(10 \mu \mathrm{g} / \mathrm{L})$, levomepromazine $(0.88 \mathrm{mg} / \mathrm{L})$, sertraline $(0.24 \mathrm{mg} / \mathrm{L})$, quetiapine $(0.40 \mathrm{mg} / \mathrm{L})$, valproic acid (22 $\mathrm{mg} / \mathrm{L})$, and caffeine $(6.4 \mathrm{mg} / \mathrm{L})$. Accidental poisoning from MDMA, buprenorphine, and levomepromazine was determined as the cause of death, with cardiomegaly as a contributing factor.

- Case 2. A 23-year-old obese woman suffering from type 2 diabetes mellitus, depression, and panic disorder had been drinking alcohol during the evening and night. She had fallen out of her bed at home and was subsequently found lifeless. She died despite resuscitation 
measures. Toxicology findings in blood were buprenorphine $(0.58$ $\mu \mathrm{g} / \mathrm{L})$ and citalopram $(<0.1 \mathrm{mg} / \mathrm{L})$. Toxicology findings in urine were buprenorphine $(81 \mu \mathrm{g} / \mathrm{L})$, norbuprenorphine $(38 \mu \mathrm{g} / \mathrm{L})$, naloxone $(120 \mathrm{mg} / \mathrm{L})$ and ethyl glucuronide $(53 \mathrm{mg} / \mathrm{L})$. Buprenorphine poisoning (manner of death undetermined) was determined as the cause of death, with morbid obesity as a contributing factor.

- Case 3. A 43-year-old epileptic man was found dead at home lying prone on the coach. He was known to have used cannabis and also drugs in excess of therapeutic doses. Toxicology findings in blood were buprenorphine $(4.4 \mu \mathrm{g} / \mathrm{L})$, norbuprenorphine $(5.3 \mu \mathrm{g} / \mathrm{L})$, THC $(20 \mu \mathrm{g} / \mathrm{L})$, THC-COOH $(230 \mu \mathrm{g} / \mathrm{L})$, and 11-hydroxy-THC $(12 \mu \mathrm{g} / \mathrm{L})$. Toxicology findings in urine were buprenorphine $(>200 \mu \mathrm{g} / \mathrm{L})$, norbuprenorphine (130 $\mu \mathrm{g} / \mathrm{L})$, THC-COOH $(3300 \mu \mathrm{g} / \mathrm{L})$, and chlorcyclizine (posit.). Accidental buprenorphine poisoning was determined as the cause of death.

\section{Discussion}

Of all buprenorphine user deaths, buprenorphine was implicated in a poisoning without other opioids in $34 \%$ (group A) and with other opioids in $13 \%$ of cases (group B); the proportion of other than buprenorphine-related poisonings was $11 \%$ (group C) and nonpoisonings $42 \%$ (group D).

Our research corroborates the previous findings of a high level of concomitant drug use in buprenorphine-related deaths. In group A buprenorphine poisonings, concomitant benzodiazepines were found in $94 \%$, illicit drugs in $63 \%$, gabapentinoids in $50 \%$, alcohol in $41 \%$, antidepressants in $32 \%$, and antipsychotics in $28 \%$ of cases. In a previous Finnish study from 2000 to 2008, Häkkinen et al. reported the presence of benzodiazepines and alcohol in $82 \%$ and $58 \%$ of fatal buprenorphine poisonings, respectively (Häkkinen et al., 2012). In a Swedish study from 2005 to 2009 , Seldén et al. reported $75 \%$ of concomitant sedative/hypnotic drugs, $24 \%$ of alcohol, and $2 \%$ pregabalin in fatal buprenorphine poisonings (Seldén et al., 2012). The prevalence of benzodiazepines in our study was thus even higher than in previous studies. We also found that concomitant gabapentinoids, especially pregabalin ( $41 \%$ ), were prevalent; this reflects the increased popularity of gabapentinoids in supratherapeutic doses among people who use drugs (Evoy et al., 2017). One explanation for the high percentages observed in our study is that the concomitant drug use is based on comprehensive laboratory analysis (not limited to blood samples), rather than survey or prescription data.

Interestingly, all buprenorphine user deaths in our material were strongly associated with polydrug use regardless of the cause of death (Fig. 3). Despite this, group A buprenorphine poisonings were characterized by a significantly higher prevalence of alcohol, benzodiazepines, and gabapentinoids than the control group D. There were no corresponding significant differences for the other types of drugs. In group A, we found a very low proportion of cases with only a single concomitant sedative/hypnotic drug present without other concomitant drugs; the percentages for benzodiazepines, alcohol, and gabapentinoids were $4 \%$, $1 \%$ and $0 \%$, respectively. This finding highlights the extensive polydrug use in the study population. At the same time, polydrug use makes it impossible to estimate the contribution of specific sedative/hypnotics to death.

Among individual benzodiazepine substances, the most prevalent findings in our study were clonazepam, alprazolam, and diazepam. The frequent occurrence of two or three individual benzodiazepine substances per death case suggests that a major proportion of the benzodiazepine findings is associated with medically non-supervised use. While prescribed benzodiazepines (especially oxazepam) are common in Finnish opioid use disorder patients, there are differences in the choice of the particular benzodiazepine between treatment facilities. Approximately a third of buprenorphine patients are prescribed benzodiazepines, and up to another third regularly use benzodiazepines that are obtained illicitly (Park et al., 2020). As our study population is not limited to OAT patients, the much greater than two thirds proportion of benzodiazepine users is plausible.

The large proportion of clonazepam detected in our study (53\% in group A) differed from a previous study in which clonazepam was detected only in $10 \%$ (Seldén et al., 2012). There is currently a clear interest in clonazepam among people who use drugs (Høiseth et al., 2015; Haukka et al., 2018). The ESCAPE Project 2017 on drug residues in used syringes from six European cities (EMCDDA, 2019b) showed that in the 284 syringes analyzed in Helsinki, Finland, the number of benzodiazepine-containing syringes was 32 , as compared to 163 buprenorphine findings and 150 findings for amphetamine or methamphetamine. The most prevalent individual benzodiazepine was midazolam in 15 syringes, while clonazepam and temazepam were the second-most prevalent in seven syringes each. These results suggest that users of buprenorphine mostly take benzodiazepines orally, whereas intravenous abuse of benzodiazepines is uncommon. The preference of midazolam over other benzodiazepines in intravenous use in the syringe residue study is probably due to the availability of a liquid midazolam formulation.

Only three (1\%) group A buprenorphine poisonings in our study population did not involve concurrent benzodiazepines, alcohol, or gabapentinoids. Among these cases, only Case 2 lacked toxicological findings other than buprenorphine. Case 1 showed toxic levels of MDMA and levomepromazine. Case 3 showed high levels of cannabis but the forensic pathologist had neither considered it to be the cause of death nor a contributing factor. Kriikku et al. found $1.3 \%-2.0 \%$ of cases without other psychoactive substances among deaths in which buprenorphine was the main cause of poisoning (Kriikku et al., 2018). Seldén et al., on the other hand, found up to $10 \%$ of such cases (Seldén et al., 2012). These percentages are certainly affected by the comprehensiveness of the laboratory analysis and by interpretations of the forensic pathologists. However, our findings confirm that fatal buprenorphine poisoning without interacting sedative/hypnotic drugs is a very rare phenomenon.

We found an annually increasing number of deaths due to buprenorphine poisoning in young people during the study period. There were significantly more individuals aged $15-24$ years in the buprenorphine poisoning group A than in any of the other groups. This finding may break the long-term trend in which age at death in fatal buprenorphine poisonings in Finland has been on the rise. The median age in group A was 31 years ( $20 \%$ females), while the median age in buprenorphine poisonings during 2010-2014 was 33 years (Kriikku et al., 2018). Young age was significantly associated with more concomitant benzodiazepine and illicit drug use. The majority ( $65 \%$ ) of individuals aged $15-24$ years died of fatal buprenorphine poisoning, whereas the cause of death in older age groups was more often unrelated to buprenorphine use. These findings may indicate more high-risk drug use among younger individuals, involving intravenous administration of buprenorphine and extensive and frequent polydrug use.

The worsening of the drug situation in Finland was indeed evident in a recent study that examined the number and age of problem drug users. There were 31,100 to 44,300 high-risk users of amphetamines and opioids (27 \% females) in Finland in 2017, which is $0.91 \%-1.29 \%$ (amphetamines $0.61-0.81 \%$, opioids $0.68-0.86 \%$ ) of Finns aged 15-64 years. The number of high-risk opioid users had nearly doubled from a previous study in 2012, and there was a particular increase in the age group of 15-24 years (Rönkä et al., 2020).

Despite guidelines that advise against additional prescription of drugs that may potentiate the respiratory depressive effects of opioids and increase risk of overdose death, these drugs are commonly prescribed to opioid-dependent individuals (Zhu et al., 2018). Mcleod et al. studied the effects of prescription of benzodiazepines, z-drugs, and gabapentinoids amongst opioid-dependent patients receiving OAT in primary care (Macleod et al., 2019). The authors found that individuals that were additionally prescribed benzodiazepines had an increased risk of death from overdose, despite remaining in treatment longer. 
Coprescription of z-drugs and gabapentinoids was also associated with increased mortality risk. However, for z-drugs there was no evidence for a dose-response effect on drug-related poisoning, and for gabapentinoids the increased mortality risk was not specific to drug-related poisoning. Park et al. pointed out that because benzodiazepines are associated with a decreased risk of OAT discontinuation and because OAT in turn is associated with significant reductions in overdose and mortality, prescribing benzodiazepines may sometimes be justified if it results in the patient staying longer in treatment and thus staying alive (Park et al., 2020). Kelty et al. compared blood toxicology in fatalities involving alcohol and other drugs in patients with an opioid use disorder treated with methadone, buprenorphine, and implant naltrexone. Their results indicated that the three medication groups had comparable susceptibilities to lethal co-intoxication and that similar drug mixtures contributed to death (Kelty et al., 2020).

In a recent study, Fugelstad et al. found that prescription opioid- and methadone-related deaths increased in the 15-29-year age group in Sweden between 2006 and 2015 (Fugelstad et al., 2020). Among the 269 methadone-related deaths, thirty-eight (14\%) were attributed to methadone only. In $76 \%$ of the cases, deaths occurred in those who had taken methadone while also using one or more benzodiazepines. Most methadone-related deaths occurred in individuals who were not prescribed methadone. Despite the fact that, unlike buprenorphine, methadone is a full agonist, there are many similarities in the deaths caused by these two opioids, such as delayed central respiratory depression, often in combination with other drugs, primarily benzodiazepines.

On the basis of a Finnish survey, Launonen et al. stated that more effort should be made to reduce concurrent use of injectable drugs during OAT by addressing concurrent substance use orders more effectively, by ensuring that patients receive an optimal buprenorphine/ naloxone dose, and by providing more psychosocial support (Launonen et al., 2016). Indeed, Heikman et al. found that inadequate doses of the OAT medicines (as experienced by the patients) were associated with higher subjective withdrawal scores, craving for opioids, and more common polydrug use (Heikman et al., 2017).

Prevention of buprenorphine user deaths should focus on reducing concomitant use of alcohol, sedative/hypnotic drugs, and illicit drugs. However, this goal is difficult to achieve due to the addictive nature of the drug combination. There is clear evidence that persons with opioid use disorders rarely prefer buprenorphine for its inherent euphorigenic properties, but the drug is used to manage opioid withdrawal symptoms or to achieve or maintain abstinence from other opioids (Alho et al., 2007; Cicero et al., 2014; Chilcoat et al., 2019). However, many persons with opioid use disorders use benzodiazepines to obtain or augment the opioid high in addition to using benzodiazepines for symptoms such as anxiety, insomnia, opioid withdrawal, and depression (Jones et al., 2012; Stein et al., 2016).

We regret to note that extensive concomitant use of benzodiazepines regardless of the cause of death masks nuanced drug interaction differences between the buprenorphine user groups. The higher prevalence of concomitant benzodiazepines and illicit drugs and the higher mortality in the age group 15-24 years than in older and more experienced users suggests particularly unsafe drug use patterns in the younger age group, which requires rapid intervention. Further research is needed to determine whether there are differences in risk between different individual sedative/hypnotic drugs in concomitant use. Another area of interest is whether the route of administration of concomitant drugs or the order in which the opioid and sedative is taken is relevant to the fatal outcome.

\section{Author contributions}

Claudia Mariottini performed the original tabulation of data and wrote the first draft manuscript. Pirkko Kriikku performed the database searches and statistical calculations and reviewed the manuscript. Ilkka Ojanperä outlined the research project and finalized the manuscript. All authors were involved in interpreting the results and editing the manuscript.

\section{Role of funding source}

Claudia Mariottini received a personal grant from the Häme Students Foundation sr, Helsinki, Finland. The funding organization had no role in the design and conduct of the study; collection, management, analysis, and interpretation of the data; preparation, review, or approval of the manuscript; or decision to submit the manuscript for publication.

\section{Declaration of Competing Interest}

The authors report no declarations of interest.

\section{Appendix A. Supplementary data}

Supplementary material related to this article can be found, in the online version, at doi:https://doi.org/10.1016/j.drugalcdep.2020.10 8345.

\section{References}

Abrahamsson, T., Berge, J., Öjehagen, A., Håkansson, A., 2017. Benzodiazepine, z-drug and pregabalin prescriptions and mortality among patients in opioid maintenance treatment - A nation-wide register-based open cohort study. Drug Alcohol Depend. $174,58-64$.

Alho, H., Sinclair, D., Vuori, E., Holopainen, A., 2007. Abuse liability of buprenorphinenaloxone tablets in untreated IV drug users. Drug Alcohol Depend. 88, 75-78.

Chilcoat, H.D., Amick, H.R., Sherwood, M.R., Dunn, K.E., 2019. Buprenorphine in the United States: motives for abuse, misuse, and diversion. J. Subst. Abuse Treat. 104, $148-157$.

Cicero, T.J., Ellis, M.S., Surratt, H.L., Kurtz, S.P., 2014. Factors contributing to the rise of buprenorphine misuse: 2008-2013. Drug Alcohol Depend. 142, 98-104.

Clausen, T., Waal, H., Thoresen, M., Gossop, M., 2009. Mortality among opiate users: opioid maintenance therapy, age and causes of death. Addiction 104, 1356-1362.

Comer, S.D., Collins, E.D., Fischman, M.W., 2002. Intravenous buprenorphine selfadministration by detoxified heroin abusers. J. Pharmacol. Exp. Ther. 301, 266-276.

Davis, M.P., Pasternak, G., Behm, B., 2018. Treating chronic pain: an overview of clinical studies centered on the buprenorphine option. Drugs 78, 1211-1228.

Degenhardt, L., Bucello, C., Mathers, B., Briegleb, C., Ali, H., Hickman, M., McLaren, J., 2011. Mortality among regular or dependent users of heroin and other opioids: a systematic review and meta-analysis of cohort studies. Addiction 106, 32-51.

EMCDDA: European Monitoring Centre for Drugs and Drug Addiction, 2019a. Finland Country Drug Report 2019 (Accessed 12 August, 2020). https://www.emcdda.euro pa.eu/publications/country-drug-reports/2019/finland_en.

EMCDDA: European Monitoring Centre for Drugs and Drug Addiction, 2019b. Drugs in Syringes From Six European Cities: Results From the ESCAPE Project 2017, Publications Office of the European Union, Luxembourg (Accessed 12 August, 2020). https://www.emcdda.europa.eu/publications/rapid-communications/drugs-in-syri nges-from-six-european-cities_en.

Evoy, K.E., Morrison, M.D., Saklad, S.R., 2017. Abuse and misuse of Pregabalin and gabapentin. Drugs 77, 403-426.

Ferrant, O., Papin, F., Clin, B., Lacroix, C., Saussereau, E., Remoué, J.E., Goullé, J.P., 2011. Fatal poisoning due to snorting buprenorphine and alcohol consumption. Forensic Sci. Int. 204, e8-11.

Finnish Customs: Finnish Customs Enforcement, 2018. Finnish Customs: Finnish Customs Enforcement (Accessed 28 September, 2020). https://tulli.fi/documents/2912305/ 4898005/Finnish\%20Customs\%20Enforcement $\% 202018 / 2181$ fc30-61fb-6680-ed0 1-ff17fc64d8b4/Finnish\%20Customs\%20Enforcement\%202018.pdf?version=1.0.

Fugelstad, A., Bremberg, S., Hjelmström, P., Thiblin, I., 2020. Methadone-related deaths among youth and young adults in Sweden 2006-15. Addiction. https://doi.org/ 10.1111/add.15152. Online ahead of print.

Gibson, A.E., Degenhardt, L.J., 2007. Mortality related to pharmacotherapies for opioid dependence: a comparative analysis of coronial records. Drug Alcohol Rev. 26, 405-410.

Häkkinen, M., Launiainen, T., Vuori, E., Ojanperä, I., 2012. Benzodiazepines and alcohol are associated with cases of fatal buprenorphine poisoning. Eur. J. Clin. Pharmacol. 68, 301-309.

Häkkinen, M., Heikman, P., Ojanperä, I., 2013. Parenteral buprenorphine-naloxone abuse is a major cause of fatal buprenorphine-related poisoning. Forensic Sci. Int. 232, 11-15.

Haukka, J., Kriikku, P., Mariottini, C., Partonen, T., Ojanperä, I., 2018. Non-medical use of psychoactive prescription drugs is associated with fatal poisoning. Addiction 113, 464-472.

Heikman, P.K., Muhonen, L.H., Ojanperä, I.A., 2017. Polydrug abuse among opioid maintenance treatment patients is related to inadequate dose of maintenance treatment medicine. BMC Psychiatry 17, 245. 
Høiseth, G., Middelkoop, G., Mørland, J., Gjerde, H., 2015. Has previous abuse of flunitrazepam been replaced by clonazepam? Eur. Addict. Res. 21, 217-221.

Jasinski, D.R., Pevnick, J.S., Griffith, J.D., 1978. Human pharmacology and abuse potential of the analgesic buprenorphine: a potential agent for treating narcotic addiction. Arch. Gen. Psychiatry 35, 501-516.

Jones, J.D., Mogali, S., Comer, S.D., 2012. Polydrug abuse: a review of opioid and benzodiazepine combination use. Drug Alcohol Depend. 125, 8-18.

Kauhanen, J., Tiihonen, J., 2017. Health risks of drugs in Finland - can the risks be managed? Duodecim 133, 34-42 (In Finnish; English abstract available).

Kelty, E., Hulse, G., 2017. Fatal and non-fatal opioid overdose in opioid dependent patients treated with methadone, buprenorphine or implant naltrexone. Int. J. Drug Policy 46, 54-60.

Kelty, E., Hulse, G., Joyce, D., 2020. A comparison of blood toxicology in fatalities involving alcohol and other drugs in patients with an opioid use disorder treated with methadone, buprenorphine, and implant naltrexone. Am. J. Drug Alcohol Abuse 46, 241-250.

Kriikku, P., Häkkinen, M., Ojanperä, I., 2018. High buprenorphine-related mortality is persistent in Finland. Forensic Sci. Int. 291, 76-82.

Launonen, E., Wallace, I., Kotovirta, E., Alho, H., Simojoki, K., 2016. Factors associated with non-adherence and misuse of opioid maintenance treatment medications and intoxicating drugs among Finnish maintenance treatment patients. Drug Alcohol Depend. 162, 227-235.

Li, X., Shorter, D., Kosten, T.R., 2016. Buprenorphine prescribing: to expand or not to expand. J. Psychiatr. Pract. 22, 183-192.

Macleod, J., Steer, C., Tilling, K., Cornish, R., Marsden, J., Millar, T., Strang, J., Hickman, M., 2019. Prescription of benzodiazepines, z-drugs, and gabapentinoids and mortality risk in people receiving opioid agonist treatment: observational study based on the UK Clinical Practice Research Datalink and Office for National Statistics death records. PLoS Med. 16, e1002965.

Marteau, D., McDonald, R., Patel, K., 2015. The relative risk of fatal poisoning by methadone or buprenorphine within the wider population of England and Wales. BMJ Open 5, e007629.

Mégarbane, B., Hreiche, R., Pirnay, S., Marie, N., Baud, F.J., 2006. Does high-dose buprenorphine cause respiratory depression?: possible mechanisms and therapeutic consequences. Toxicol. Rev. 25, 79-85.

Orman, J.S., Keating, G.M., 2009. Buprenorphine/naloxone: a review of its use in the treatment of opioid dependence. Drugs 69, 577-607.

Park, T.W., Larochelle, M.R., Saitz, R., Wang, N., Bernson, D., Walley, A.Y., 2020. Associations between prescribed benzodiazepines, overdose death and buprenorphine discontinuation among people receiving buprenorphine. Addiction 115, 924-932.

Rönkä, S., Ollgren, J., Alho, H., Brummer-Korvenkontio, H., Gunnar, T., Karjalainen, K., Partanen, A., Väre, T., 2020. The prevalence of high-risk amphetamine and opioid use in Finland in 2017. Duodecim 136, 927-935 (In Finnish; English abstract available).

Seldén, T., Ahlner, J., Druid, H., Kronstrand, R., 2012. Toxicological and pathological findings in a series of buprenorphine related deaths. Possible risk factors for fatal outcome. Forensic Sci. Int. 220, 284-290.
Simonsen, K.W., Kriikku, P., Thelander, G., Edvardsen, H.M.E., Thordardottir, S., Andersen, C.U., Jönsson, A.K., Frost, J., Christoffersen, D.J., Delaveris, G.J.M., Ojanperä, I., 2020. Fatal poisoning in drug addicts in the Nordic countries in 2017. Forensic Sci. Int. 313 (110343) https://doi.org/10.1016/j.forsciint.2020.110343. Epub 2020 May 20.

Sordo, L., Barrio, G., Bravo, M.J., Indave, B.I., Degenhardt, L., Wiessing, L., Ferri, M., Pastor-Barriuso, R., 2017. Mortality risk during and after opioid substitution treatment: systematic review and meta-analysis of cohort studies. BMJ. 357, j1550.

Stein, M.D., Kanabar, M., Anderson, B.J., Lembke, A., Bailey, G.L., 2016. Reasons for benzodiazepine use among persons seeking opioid detoxification. J. Subst. Abuse Treat. 68, 57-61.

Tracqui, A., Kintz, P., Ludes, B., 1998. Buprenorphine-related deaths among drug addicts in France: a report on 20 fatalities. J. Anal. Toxicol. 22, 430-434.

Uosukainen, H., Kauhanen, J., Voutilainen, S., Föhr, J., Paasolainen, M., Tiihonen, J., Laitinen, K., Onyeka, I.N., Bell, J.S., 2013a. Twelve-year trend in treatment seeking for buprenorphine abuse in Finland. Drug Alcohol Depend. 127, 207-214.

Uosukainen, H., Kauhanen, J., Bell, J.S., Ronkainen, K., Tiihonen, J., Föhr, J., Onyeka, I. N., Korhonen, M.J., 2013b. Mortality among clients seeking treatment for buprenorphine abuse in Finland. Drug Alcohol Depend. 133, 391-397.

Uosukainen, H., Ilomäki, J., Kauhanen, J., Tacke, U., Föhr, J., Tiihonen, J., Bell, J.S., 2014. Factors associated with buprenorphine compared to amphetamine abuse among clients seeking treatment in Finland. J. Subst. Abuse Treat. 46, 561-566.

Walsh, S.L., Preston, K.L., Bigelow, G.E., Stitzer, M.L., 1995. Acute administration of buprenorphine in humans: partial agonist and blockade effects. J. Pharmacol. Exp. Ther. 274, 361-372.

White, M., Burton, R., Darke, S., Eastwood, B., Knight, J., Millar, T., Musto, V., Marsden, J., 2015. Fatal opioid poisoning: a counterfactual model to estimate the preventive effect of treatment for opioid use disorder in England. Addiction 110, 1321-1329.

Wightman, R.S., Perrone, J., Scagos, R., Krieger, M., Nelson, L.S., Marshall, B.D.L., 2020 Opioid overdose deaths with buprenorphine detected in postmortem toxicology: a retrospective analysis. J. Med. Toxicol. https://doi.org/10.1007/s13181-020-007953. Online ahead of print.

Wikner, B.N., Öhman, I., Seldén, T., Druid, H., Brandt, L., Kieler, H., 2014. Opioid-related mortality and filled prescriptions for buprenorphine and methadone. Drug Alcohol Rev. 33, 491-498.

Yassen, A., Olofsen, E., Romberg, R., Sarton, E., Teppema, L., Danhof, M., Dahan, A., 2007. Mechanism-based PK/PD modeling of the respiratory depressant effect of buprenorphine and fentanyl in healthy volunteers. Clin. Pharmacol. Ther. 81, 50-58.

Yokell, M.A., Zaller, N.D., Green, T.C., Rich, J.D., 2011. Buprenorphine and buprenorphine/naloxone diversion, misuse, and illicit use: an international review. Curr. Drug Abuse Rev. 4, 28-41.

Zhu, Y., Coyle, D.T., Mohamoud, M., Zhou, E., Eworuke, E., Dormitzer, C., Staffa, J., 2018. Concomitant use of buprenorphine for medication-assisted treatment of opioid use disorder and benzodiazepines: using the prescription behavior surveillance system. Drug Alcohol Depend. 187, 221-226. 